\title{
Chromophobe renal cell carcinoma: current and controversial issues
}

\author{
${\text { Holger } \mathrm{Moch}^{1} \text {, Riuko OHashi }}^{2}$ \\ ${ }^{1}$ Department of Pathology and Molecular Pathology, University Hospital Zurich, Zurich, \\ Switzerland; ${ }^{2}$ Histopathology Core Facility, Niigata University Faculty of Medicine, Niigata, \\ Japan
}

\begin{abstract}
Summary
It has been 35 years since Professor Thoenes and his colleagues discovered chromophobe renal cell carcinoma (RCC). Since then, our knowledge about this tumour entity has changed and novel tumour entities have been discovered. The aim of this review is to discuss recent molecular findings and open questions in diagnosing chromophobe-like/oncocytic neoplasms. The broader differential diagnosis of chromophobe-like and oncocytomalike neoplasms includes SDH-deficient renal cell carcinoma, fumarate hydratase $(\mathrm{FH})$ deficient RCC, epitheloid angiomyolipoma ('oncocytoma like'), MiT family translocation RCC and the emerging entity of eosinophilic solid and cystic renal cell carcinoma. After separation of these tumours from chromophobe RCC, it becomes evident that chromophobe RCC are low malignant tumours with a $5-6 \%$ risk of metastasis. Recent next generation sequencing (NGS) and DNA methylation profiling studies have confirmed Thoenes' theory of a distal tubule derived origin of chromophobe RCC and renal oncocytomas. Comprehensive genomic analyses of chromophobe RCC have demonstrated a low somatic mutation rate and identified TP53 and PTEN as the most frequently mutated genes, whereas 'unclassified' RCC with oncocytic or chromophobe-like features can show somatic inactivating mutations of TSC2 or activating mutations of MTOR as the primary molecular alterations. For the future, it would be desirable to create a category of 'oncocytic/chromophobe RCC, NOS' with the potential of further molecular studies for identification of TSC1/2 mutations in these rare tumours.
\end{abstract}

Key words: Molecular pathology; classification; differential diagnosis; immunohistochemistry; history.

Received 7 September, accepted 8 September 2020 Available online 9 November 2020

\section{RECOGNITION OF CHROMOPHOBE RENAL CELL CARCINOMA}

In the 1975 United States Armed Forces Institute of Pathology (AFIP) Atlas of Tumour Pathology ${ }^{1}$ and the 1981 World Health Organization (WHO) classification, ${ }^{2}$ renal cell carcinoma (RCC) was mainly diagnosed as 'renal adenocarcinoma', but it was evident that histological subtyping was of prognostic significance. ${ }^{3}$ Classification attempts before 1950 included subtypes according to the predominant cytoplasmic or architectural features with clear cell carcinomas, papillary carcinomas and granular cell carcinomas. ${ }^{4}$ Renal tumours that were composed of 'oncocytes' had been already described in 1942. This name came from the dominant cell type of large, eosinophilic cells with granular cytoplasm. Later, oncocytoma was accepted as a benign renal tumour entity, but there were already descriptions of malignant forms of oncocytomas, which were probably chromophobe RCC. ${ }^{3,5}$ In 1985 and 1988, Thoenes et al. reported on RCCs composed of 'chromophobe' cells., This designation resulted from an observation of Bannasch et al. in 1974 in nitrosomorpholine-induced renal neoplasia in rats. ${ }^{8}$ These tumours in rats showed a peculiar histomorphology; by light microscopy, 'chromophobe' cells had a slightly opaque finely reticular cytoplasm when stained with haematoxylin and eosin. In the 1980s, classification proposals for human RCC used characteristic cellular features for their entities. With the recognition of a 'chromophobe' RCC subtype, Thoenes et al. proposed in 1986 the Mainz classification system (Fig. 1) with tumour subtypes classified consequently on the basis of predominant cytoplasmic staining characteristics. ${ }^{9}$ They separated clear cell carcinoma from chromophilic carcinoma and chromophobe RCCs, and added Bellini duct carcinoma on the basis of the 'cell of origin' concept. Cells of chromophobe RCC were distinguished from the clear cells of clear cell carcinoma and eosinophilic cells of 'chromophilic' papillary carcinoma. In contrast to oncocytoma, chromophobe RCC showed a strong positive reaction of their cytoplasm with Hale's colloidal iron method. In the following years, the Mainz classification was validated by cytogenetic studies, mainly performed by Kovacs. ${ }^{10-12}$ Most importantly, chromophobe RCC was characterised by a unique genetic background with loss of heterozygosity $1,2,6,10,13,17,21$ and hypodiploidy on flow cytometry studies in addition to its typical histological appearance. ${ }^{13}$ At the 1997 Heidelberg conference, the molecular background of different renal cancer subtypes was introduced into a classification system. ${ }^{14}$ As a result of the Heidelberg/Rochester consensus conferences, the 1998 WHO classification gave chromophobe RCC its own entity, 12 years after the Mainz classification. ${ }^{15}$ The 2004 and 2016 WHO classifications define chromophobe RCC as the third most common subtype of RCC. ${ }^{16,17}$ 


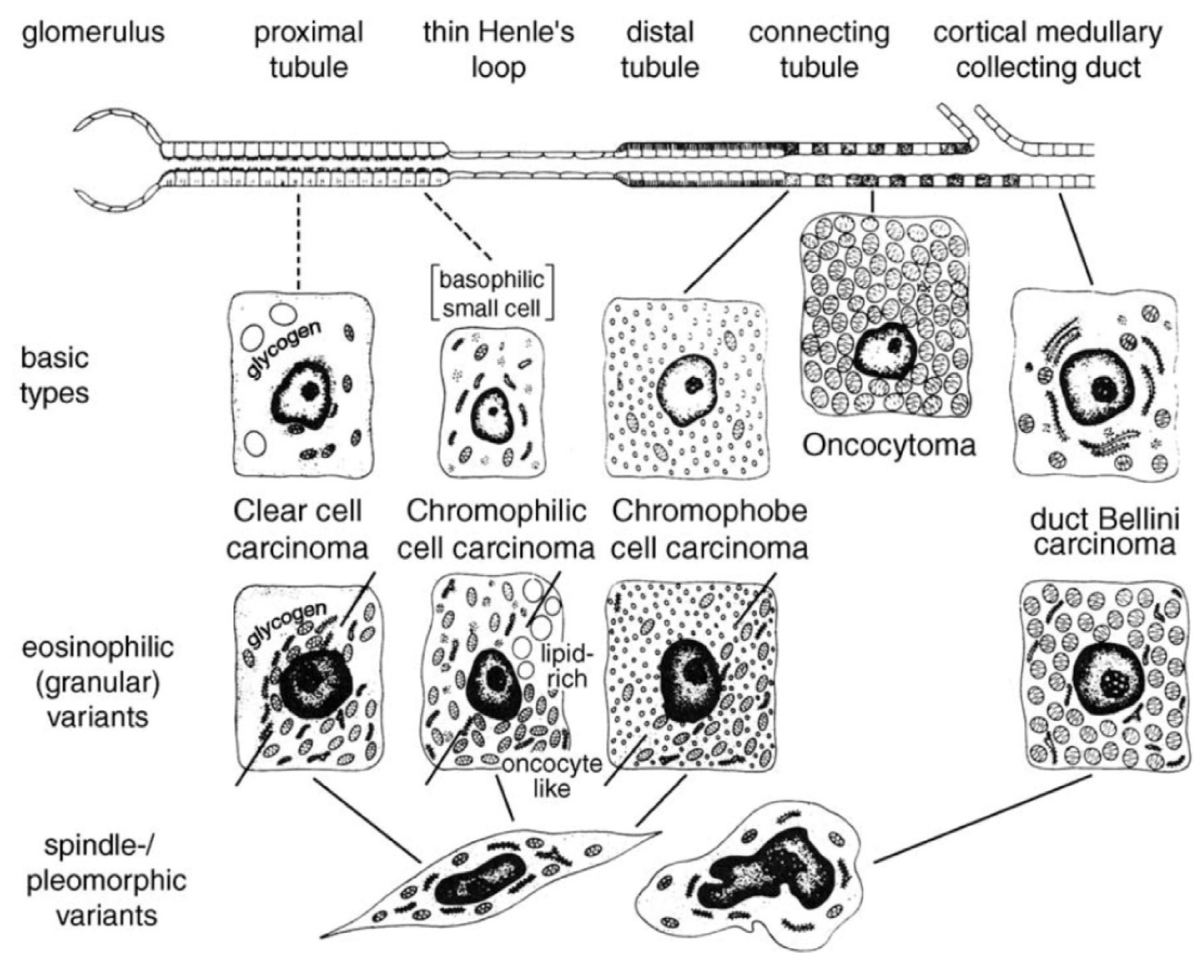

Fig. 1 Mainz Classification with a scheme of the various nephron/collecting duct segments and their different phenotypical relation to the classified epithelial renal cell tumours.

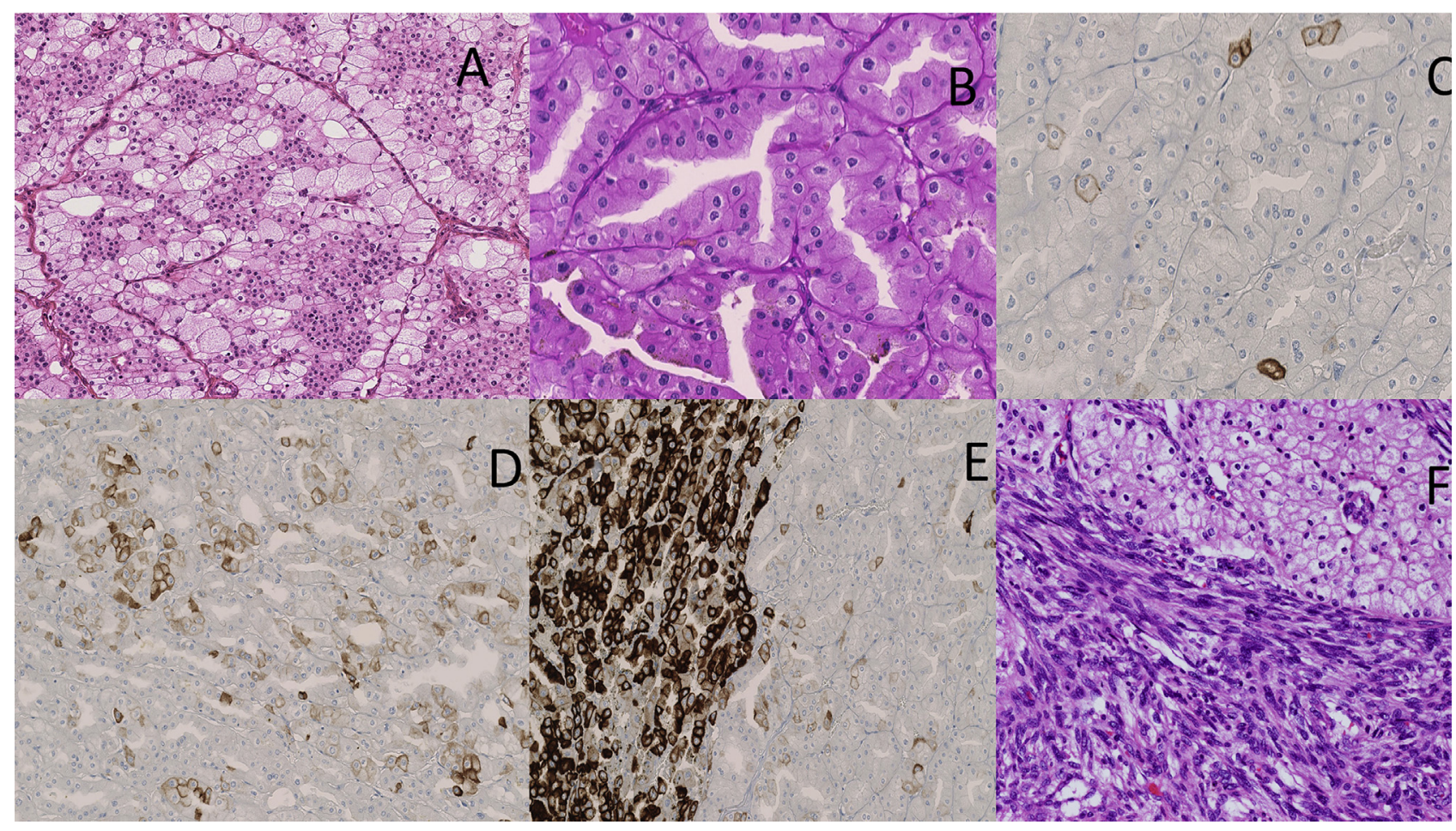

Fig. 2 Morphological heterogeneity of chromophobe renal cell carcinoma (RCC). (A) Chromophobe RCC consisting of both cell types, eosinophilic and pale cells. (B-E) Intratumoural heterogeneity of CK7 staining in chromophobe RCC. (B) Tumour area almost purely composed of eosinophilic cells. Note perinuclear halos. (C) Tumour area with CK7 positivity in single cells, similar to oncocytomas. Note bi-nucleated tumour cells. (D) Tumour area with groups of CK7-positive cells, typical for chromophobe RCC. (E) Tumour area with diffuse and strong CK7 staining. (F) Chromophobe RCC with sarcomatoid differentiation. 


\section{EPIDEMIOLOGY, MACROSCOPY, HISTOPATHOLOGY}

Since the first description by Thoenes et al., epidemiology and pathological features of chromophobe RCC have been extensively studied. ${ }^{18-23}$ Chromophobe RCC accounts for approximately $5-7 \%$ of RCC. Most tumours are sporadic. Birt-Hogg-Dubé (BHD) syndrome, an autosomal dominant disorder associated with mutation in the Folliculin gene, ${ }^{24}$ and Cowden syndrome with germline mutations in PTEN are associated with a higher incidence of chromophobe-like or oncocytoma-like neoplasms.

Chromophobe RCC are characteristically well circumscribed but not encapsulated. Whereas most oncocytoma have a brown or mahagony colour, the cut surface of classic chromophobe RCC is grey or light tan. Histologically, they grow predominantly in solid sheets, separated by vascular septs (Fig. 2A,B). Some tumours show variable nested, trabecular, alveolar, microcystic or even papillary patterns. ${ }^{25}$ A small percentage exhibits sarcomatoid growth ${ }^{26}$ (Fig. 2F). Classic tumours show predominance of pale cells with clear cytoplasm. The cytoplasm is translucent and finely reticulated, sometimes microvesiculated. Some larger cells with more voluminous clear to foamy ('hydropic') cytoplasm are often present among pale cells. Another cell type is characterised by densely eosinophilic or granular cytoplasm (Fig. 2B). Pale and eosinophilic cell types can be mixed (Fig. 2A). Hyperchromatic nuclei with irregular, wrinkled outlines ('raisinoid') are most characteristic. Another characteristic feature is presence of perinuclear cytoplasmic clarity (so called perinuclear halos). Binucleated cells are present in virtually all cases. Cell membranes usually appear prominent ('plant celllike'), an important criterion compared to oncocytoma. Hyperchromatic bizarre nuclear atypia similar to those in renal oncocytoma can be common. The prevalence of sarcomatoid differentiation ranges from $1.8 \%$ to $8.8 \% .{ }^{27,28}$ Mitotic activity is very uncommon in chromophobe RCC. Since the first description of chromophobe RCC, the differential diagnosis between renal oncocytoma and chromophobe RCC remains difficult in some cases. A recent survey among urological pathologists regarding oncocytic tumours showed that most pathologists used immunohistochemistry for this separation. ${ }^{29}$ More than one mitotic figure was regarded as incompatible with oncocytoma diagnosis by many uropathologists. Minor areas with nuclear wrinkling, focal perinuclear clearing, and multinucleation did not necessarily exclude oncocytoma.

\section{ELECTRON MICROSCOPY, HISTOCHEMISTRY, AND IMMUNOHISTOCHEMISTRY}

For many years, electron microscopy was used to diagnose oncocytomas and chromophobe RCC. Thoenes et al. reported on vesicular structures possibly derived from the endoplasmic reticulum or from mitochondria chromophobe RCC and oncocytomas. ${ }^{7,9}$ Several ultrastructural studies have shown that the typical cells of chromophobe RCC ('pale cells') are characterised by numerous cytoplasmic microvesicles, a feature probably related to defective mitochondrial development. In more eosinophilic cells of chromophobe RCC, mitochondria are very abundant. ${ }^{2,6-30}$ Thoenes et al. also used colloidal (Hale's) iron staining, demonstrating a variable granular or reticular and diffuse cytoplasmic staining in most chromophobe RCC in contrast to oncocytomas. However, colloidal (Hale's) iron staining is nowadays less popular, because some chromophobe RCC show only focal or weak or even luminal-type staining. ${ }^{29}$ Immunohistochemically, CK7 is a very important marker, showing diffuse expression in more than $75 \%$ of chromophobe $\mathrm{RCC}^{31}$ (Fig. 2C-E). Occasionally, there are only a few clusters of weak cells with membranous accentuation. Such CK7positive cell clusters should not be present in oncocytomas, but CK7-positive cells can be present around the central scar of an oncocytoma. CD117 and Ksp-Cadherin are diffusely positive in the overwhelming majority of chromophobe RCCs. Most cases also show positivity with MOP-31, Claudin-7 and EpCAM (BerEP4). ${ }^{32}$ CA9 is negative and also CD10 is usually negative but may show focal positivity. ${ }^{33}$ Rare CK7-positive cells $(\leq 5 \%$ as single cells, not clusters) are regarded as most supportive of oncocytoma. ${ }^{29}$

\section{MOLECULAR STUDIES AND THE 'CELL OF ORIGIN' THEORY}

Thoenes assumed that chromophobe RCC had a different histogenetic derivation than clear cell and other RCCs. ${ }^{34-36}$ On the basis of a different histology and immunoprofile, he argued that chromophobe renal cancer and oncocytoma were derived from the intercalated cells of the distal tubules in the renal cortex (Fig. 1). This concept is still controversial, because the cancer stem cell theory with tumourigenic stem cells rather than terminally differentiated tubular cells is also relevant for many RCC subtypes. ${ }^{37,38}$ Interestingly, a recent next generation sequencing (NGS) analysis identified FOXI1, RHCG, and LINC01187 in classic and eosinophilic chromophobe RCCs, as well as metastatic chromophobe RCC. ${ }^{39}$ These biomarkers are also expressed in other oncocytic renal neoplasms, including unclassified RCC with oncocytic features, hybrid oncocytic and chromophobe tumours, and oncocytomas, but not in other renal tumour subtypes. FOXI1 is an essential transcription factor for differentiation of distal tubule intercalated cells. This finding is somehow in line with Thoenes' 'cell of origin' theory for oncocytic renal tumours. Recent DNA methylation profiling and single cell sequencing studies have identified chromophobe RCC specific methylation with similarities to distal tubule methylation patterns. ${ }^{40,41}$

Various cytogenetic, comparative genomic hybridisation and recent molecular and proteome studies have confirmed the very unique and characteristic genotype, with multiple chromosomal losses of chromosomes 1, 2, 6, 10, 13, 17, 21 and sex chromosome in the majority of chromophobe RCCs. ${ }^{13,42,43}$ Genomic instability, including whole chromosome aneuploidy, is a hallmark of human cancer. Given the level of chromosomal losses in chromophobe RCC, tumour growth must be the consequence of a special molecular pathway. The phenomenon of tumour cell growth in spite of multiple chromosomal losses can be potentially explained by involvement of CYCLOPS (Copy number alterations Yielding Cancer Liabilities Owing to Partial losS) genes. CYCLOPS genes receive little feedback regulation in their expression when altered by somatic copy number alterations. Splicing factor 3B subunit 1 (SF3B1) belongs to this group of CYCLOPS genes and has been recently identified as a potential novel, non-driver cancer gene in chromophobe RCC. ${ }^{44}$

Given an accumulation of mitochondria in chromophobe RCC and oncocytoma, it is tempting to search for alterations 
in mtDNA. Indeed, some studies have disclosed frequent somatic mtDNA mutations in oncocytoma and chromophobe RCC, ${ }^{45-47}$ but mtDNA mutations are not specific for chromophobe RCC. ${ }^{48}$

Comprehensive genomic analyses of chromophobe RCC cohorts demonstrated a low somatic mutation rate in chromophobe RCC and identified TP53 and PTEN as the most frequently mutated genes. ${ }^{48-51}$ Mutation rates of TP53 and PTEN were higher in chromophobe RCC patients with metastatic disease $\mathrm{e}^{52}$ and with sarcomatoid features.

$C D K N 1 A$, which resides in $6 \mathrm{p} 21.2$, is affected by frequent loss of one chromosome 6 allele in chromophobe RCC. ${ }^{53}$ Analysis of TCGA data of chromophobe RCC demonstrated that loss of one $C D K N 1 A$ allele was closely linked to lower CDKN1A mRNA expression levels. It has been recently shown that decreased $\mathrm{CDKN} 1 \mathrm{~A}$ expression at mRNA and protein levels were associated with short overall survival and were independent predictors of prognosis in chromophobe RCC.

Other NGS analyses as well as the combination of gene expression and proteome profiles, high throughput SNP genotyping, and pathway analysis have been used to distinguish chromophobe RCC from oncocytoma and confirm dysregulated pathways of c-erbB2 and mammalian target of rapamycin (mTOR) signalling in chromophobe RCC. ${ }^{39,50,54-57}$

\section{ARE THERE SUBTYPES OF CHROMOPHOBE RCC?}

\section{Eosinophilic subtype}

Thoenes et al. used the term 'chromophobe cell' for larger cells with reticular, but not clear cytoplasm and prominent cell membranes ('plant cell-like'). ${ }^{7}$ Three years later, these authors described eosinophilic cells with smaller size and with fine oxyphilic granularity as a second cell component of chromophobe RCC. ${ }^{6}$ Crotty et al. used the term 'pale cell' instead of the formerly used term 'chromophobe cell', and considered 'pale cell' and 'eosinophilic cell' as two main cell types in chromophobe RCC. ${ }^{18}$ Most chromophobe RCCs consist of both cell types, which are typically mixed, with eosinophilic cells usually arranged at the centre and pale cells usually arranged at the periphery of the sheets or nests. The current 2016 WHO classification states that eosinophilic chromophobe RCC 'is almost purely composed of eosinophilic cells' and that 'the majority of cells should be eosinophilic cells', ${ }^{17}$ but there is currently a lack of exact criteria to clearly define the eosinophilic subtype of chromophobe RCC. As a consequence of this lack of stringent criteria for subtyping chromophobe RCC, distribution of chromophobe RCC variants varies extremely between different studies and it is difficult to demonstrate molecular differences between both groups. ${ }^{58,59}$ Ohashi et al. have recently shown that there is no difference in the prognosis of 'classic' and 'eosinophilic' chromophobe RCC. ${ }^{58}$ Therefore, the value of reporting the eosinophilic variant of chromophobe RCC is to remind people that they can be mistaken for oncocytomas.

\section{Hybrid oncocytic and chromophobe tumours}

Some chromophobe tumours demonstrating nuclear pleomorphism and mitotic index beyond that acceptable for oncocytoma were initially described in patients with BHD syndrome. By conventional pathological examination, hybrid oncocytic and chromophobe tumours harbour a mixture of cells with morphological and immunophenotypical features that overlap with those of renal oncocytoma and chromophobe RCC. Therefore, the term 'hybrid oncocytic and chromophobe tumour' was proposed ${ }^{20}$ and is now variably used in several scenarios, including tumours in BHD syndrome, oncocytomatosis and for sporadic cases. ${ }^{60-62}$ Unfortunately, the morphological criteria are not exactly defined. Some hybrid oncocytic and chromophobe tumours show a mosaic pattern with defined renal oncocytoma-like zones with solid nests/alveoli in close contact to chromophobe RCC-like zones (Fig. 2), whereas others show an ambiguous morphology with oncocytoma-like architecture, but absence of nuclear wrinkling and perinuclear halos as seen in the extent of chromophobe RCC.

The 2016 WHO classification includes a statement that a small subset of tumours have overlapping histology between oncocytoma and chromophobe RCC and recommends that such tumours should be designated as hybrid oncocytic and chromophobe tumour. There is evidence that the metastatic rate of hybrid oncocytic and chromophobe tumours ranges between $2 \%$ in a sporadic setting ${ }^{20,60,63-67}$ and $5 \%$ in a BHD syndrome setting. ${ }^{68,69}$ This is comparable to chromophobe RCC with a low metastatic rate of $<10 \%$. The designation of hybrid oncocytic and chromophobe tumour as its own tumour category is controversial, with authors suggesting that hybrid oncocytic and chromophobe tumours represent a variant of classic renal oncocytoma and others as variant of the eosinophilic variant of chromophobe RCC. ${ }^{60,61}$ A very recent and comprehensive study by Ruiz-Cordero et al. studied hybrid oncocytic and chromophobe tumour by gene expression profiling and targeted NGS and compared the results with chromophobe RCC and renal oncocytoma. ${ }^{62}$ Hybrid oncocytic and chromophobe tumours were more frequently multifocal and did not exhibit mutations in genes that are recurrently mutated in renal oncocytoma or chromophobe RCC, but they showed copy number alterations primarily involving losses in chromosomes 1 and $\mathrm{X} / \mathrm{Y}$. mRNA transcript data separated hybrid oncocytic and chromophobe tumour from renal oncocytoma and chromophobe RCC. Based on these results, the authors concluded that hybrid oncocytic and chromophobe tumour represents a renal tumour variant that is intermediate between renal oncocytoma and chromophobe RCC.

A recent survey among uropathologists revealed that for tumours with mixed or inconclusive features, many participants use an intermediate diagnostic category that does not label the tumour as unequivocally benign or malignant, typically 'oncocytic neoplasm' or 'tumour' with comment. ${ }^{29}$ Therefore, most participants at the International Society of Urological Pathology (ISUP) conference indicated that they view hybrid oncocytic and chromophobe tumour as a subset of chromophobe RCC. ${ }^{70}$ Overlapping histology between oncocytoma and chromophobe RCC reflects intratumoural heterogeneity of chromophobe RCC rather than its own subtype.

\section{Is oncocytoma a precursor lesion of chromophobe RCC?}

Thoenes et al. argued that there are no precursor lesions of chromophobe RCC. Given the similarity of the eosinophilic 
variant of chromophobe RCC and oncocytoma, one might hypothesise that oncocytoma represents the benign counterpart of chromophobe RCC. In a recent study, almost all eosinophilic and all classic chromophobe RCC revealed chromosome 1 loss, suggesting that this may be an early event in chromophobe RCC tumourigenesis. The only molecular alteration shared by chromophobe RCC and renal oncocytoma is loss of chromosome $1,{ }^{58,71-73}$ consistent with a speculation by Tan et al. that this may represent an early event in neoplastic transformation of a common progenitor cell in both chromophobe RCC and renal oncocytoma. ${ }^{54}$ In oncocytomas, chromosome 1 loss may precede other molecular events leading to malignancy in lesions that progress to chromophobe RCC. This situation is comparable to chromosome $3 p$ loss in clear cell RCC, which is thought to be an early event in carcinogenesis of ccRCC.

\section{CHROMOPHOBE-LIKE AND ONCOCYTOMA- LIKE NEOPLASMS: RECENT DEVELOPMENTS IN CLASSIFICATION}

\section{Differential diagnosis}

During the last decade, unequivocal recognition of chromophobe RCC with a typical histology and immunophenotype has allowed the separation of other renal tumour entities with oncocytoma/chromophobe-like histomorphology. The most important differential diagnosis is SDH-deficient RCC, ${ }^{74,75}$ a tumour entity very similar to chromophobe RCC. It is important to recognise these tumours because they represent a hereditary tumour entity. The broader differential diagnosis of chromophobe-like and oncocytoma-like neoplasms may now include tumours occurring in patients with BHD syndrome, fumarate hydratase $(\mathrm{FH})$-deficient $\mathrm{RCC}$, epitheloid angiomyolipoma ('oncocytoma-like'), MiT family (TFE3 or TFEB) translocation RCC and the emerging entity of eosinophilic solid and cystic (ESC) RCC with a characteristic CK20 expression.

\section{Tumours with TSC alterations}

Most importantly, recent studies have identified many tumours with eosinophilic cytoplasm and oncocytic or chromophobe-like features in the group of 'unclassified' RCC. Li et al. reviewed 33 unclassified RCCs with predominantly eosinophilic cytoplasm in patients aged 35 years or younger. ${ }^{76}$ They identified SDHB-deficient, FH-deficient and ESC cases, but 33\% remained 'unclassified'. Perrino et al. analysed 136 unclassified RCC and assigned them to the following morphological groups: predominantly oncocytoma/chromophobe RCC-like; clear cell RCC-like; papillary RCC-like; collecting duct-like; and pure sarcomatoid differentiation. ${ }^{77}$ The majority $(73 \%)$ was predominantly renal oncocytoma-like/chromophobe RCC-like phenotype. Interestingly, different groups have very recently analysed 'unclassified' RCC with chromophobe-like or renal oncocytoma-like RCC and with eosinophilic or vacuolated cytoplasm by targeted NGS. Although the morphology of these cases was very close to renal oncocytoma or the eosinophilic variant of chromophobe RCC, these tumours ended up in the 'unclassified' RCC category because of an unusual histology or immunophenotype with a dense and more abundant eosinophilic cytoplasm, diffuse staining of CK7, absent to weak staining of CK20 or positivity for
P504S. ${ }^{78,79}$ Chen et al. studied five cases and Tjota et al. 18 cases. Both groups identified somatic inactivating mutations of $T S C 2$ or activating mutations of $M T O R$ as the primary molecular alterations, consistent with hyperactive mTOR complex 1 (mTORC1) signalling in most chromophobe-like or renal oncocytoma-like cases.

ESC RCC with CK20 expression can also show TSC gene mutations or biallelic losses. ${ }^{80}$ Interestingly, some ESC RCC have solid areas with chromophobe-like appearance. ${ }^{81}$ Moreover, ESC tumours have recently been described as a sporadic form of RCC with histological similarity to a subset of renal tumours encountered in TSC patients. Some authors argue that somatic mutations of TSC 2 or MTOR characterise a morphologically distinct subset of sporadic RCC with eosinophilic and vacuolated cytoplasm. However, TSC/ MTOR associated neoplasms are a morphologically and immunohistochemically heterogeneous group. TSC/MTOR associated neoplasms include eosinophilic renal tumours with a chromophobe-like appearance with perinuclear halos. Some of these tumours are diffusely positive for CK7 but negative (or only focally positive) for CK20. Trpkov et al. proposed the term 'low grade oncocytic tumours' (LOT) with CD117 negativity and CK7 positivity as an emerging renal tumour entity with indolent clinical behaviour, ${ }^{82}$ but further studies are warranted to prove that LOT really represents a distinct type of tumour. For the time being, they should be regarded as variant of unclassified 'chromophobe-like' RCC. So-called RCC 'with prominent leiomyomatous stroma' also frequently harbour TSC1/TSC2, MTOR, and/or ELOC (TCEB1) mutations, consistent with hyperactive mTOR complex. ${ }^{83}$ These tumours can have some morphological overlap with ccRCC and clear cell papillary RCC, supporting the hypothesis that previously published TCEBI (ELOC) mutated RCCs are identical, and indistinguishable from a subset of hereditary TSC associated RCCs, originally described as 'RAT-like' or 'TSC associated papillary type.'

In summary, it would be desirable to create a new category of 'oncocytic/chromophobe RCC, NOS'. The main advantage for creating this category is the potential of further molecular studies for identification of TSC1/2 mutations. According to recently published data, such tumours have a good prognosis, but identification of TSC mutations by NGS could suggest a treatment by mTOR inhibitors. In contrast, a category of TSC1/2 mutated RCC would encompass a category of tumours with an extremely broad histological spectrum, which is only molecularly defined and cannot be diagnosed by histology alone.

\section{PROGNOSIS AND GRADING OF CHROMOPHOBE RCC}

Thoenes et al. had already argued that chromophobe RCC may have a better prognosis than clear cell RCC, but his series of 13 and 33 tumours were too small to prove this hypothesis. ${ }^{6,7}$ Meanwhile several large studies have indicated that prognosis of chromophobe RCC is much better than that of clear cell RCC and papillary RCC. Most chromophobe RCC have a favourable outcome and low risk of metastasis, but there is evidence that chromophobe RCC have a predisposition to metastasise into the liver. ${ }^{84}$ Ten year overall survival rates of between 80 and $90 \%$ have been reported. ${ }^{20,22,85,86}$ It is important to note that tumour specific survival or time to tumour progression are much more 
important than overall survival measures, because death of disease occurs only in about $5-6 \%$ of patients with chromophobe RCC. ${ }^{26}$ Clinically, it would be extremely helpful to identify this small subgroup at increased risk for metastasis.

Numerous studies have confirmed that tumour size and the presence of sarcomatoid morphology indicates poor prognosis and increased risk of metastatic development for chromophobe RCC. ${ }^{23,28,85-88}$ Tumour grade is also important, but the four tiered nuclear grading system proposed by ISUP could not be validated for chromophobe RCC, because they have an innate constitutive atypia including prominent nucleoli, nuclear irregularities and bi-nucleation. ${ }^{89}$ In the past, there have been several attempts to develop a grading system for chromophobe RCC, ${ }^{20-22,27,85,86,90,91}$ considering the inherent geographic nuclear crowding and presence of anaplasia. Paner et al. suggested a three tiered chromophobe tumour grading scheme and supplemented nuclear grading with additional variables including geographic nuclear crowding and objective nuclear size. ${ }^{86}$ With this approach, the majority of chromophobe RCCs are of a lower grade, but there is inter- and intra-observer variability in the identification of nuclear crowding and nuclear pleomorphism. Lohse et al. applied a four tiered standardised grading for chromophobe RCC and demonstrated a significant overlap in grades 3, 2 and 1 chromophobe RCC. ${ }^{92}$

Recently, a two tiered grading system (low vs high grade) was proposed by Ohashi et al., using sarcomatoid differentiation and presence of tumour necrosis as parameters. ${ }^{26}$ The advantages of this two tiered grading system over previous proposals of three or four tiered grading systems, are a high to very high concordance between different pathologists, and a high reliability in identification of patients with increased risk of chromophobe RCC progression. Metastasis of low grade tumours was absent in four different cohorts from Japan, Germany, Switzerland and Italy.

\section{TREATMENT OF METASTATIC CHROMOPHOBE RCC}

Patients with high grade tumours (sarcomatoid differentiation and/or tumour necrosis) should have a stringent follow-up because of their increased risk of metastasis. ${ }^{23}$ Because metastasis of chromophobe RCC is very rare, dedicated prospective clinical trials for metastatic chromophobe RCC are not available and patients are treated as non-clear cell RCC. Favourable responses to VGF-tyrosine kinase inhibitor agent, mTOR inhibitors and immune checkpoint inhibitors have been reported. Sarcomatoid differentiation in chromophobe RCC is an indicator of limited response to systemic therapy and poor overall survival. ${ }^{28}$ However, the immunological landscape of renal tumour with sarcomatoid areas shows a different molecular background with frequent expression of programed cell death ligand-1 (PD-L1) and high levels of tumour infiltrating lymphocytes. ${ }^{93,94}$ These determinants explain the activity of immune checkpoint inhibitors in RCC with sarcomatoid differentiation. This has been confirmed by retrospective studies and subgroup analyses of large randomised phase 3 trials.

Therefore, immune checkpoint inhibitor combinations could also be relevant in patients with metastatic chromophobe RCC with sarcomatoid differentiation. ${ }^{95,96}$ Patients with metastatic chromophobe RCC might be considered for targeted NGS testing. If there is a molecular mutation, appropriate molecular targeted therapy can be provided. This is particularly critical for TSC associated 'chromophobe-like' RCCs as there are mTOR inhibitors currently available for the treatment of RCCs. ${ }^{97} \mathrm{~A}$ few case reports have demonstrated clinical benefit in using mTOR inhibitors to treat TSC associated RCCs, including complete response in a case of sporadic, metastatic ESC RCC. ${ }^{78,98}$ Interestingly, one of the cases described as responding to mTOR inhibitor therapy was originally diagnosed as chromophobe RCC. The patient was found to have a germline TSC1 mutation without other characteristics of a TSC tumour. $^{99}$

Conflicts of interest and sources of funding: This work was supported in part by Niigata Foundation for the Promotion of Medicine (2015, to RO), Japan Society for the Promotion of Science Grant-in-Aid for Scientific Research (No. JP20K07404, to RO), and the Swiss National Science Foundation grant (No. S-87701-03-01, to HM). The authors state that there are no conflicts of interest to disclose.

Address for correspondence: Prof Holger Moch, Department of Pathology and Molecular Pathology, University Hospital Zurich, Schmelzbergstrasse 12, CH-8091 Zurich, Switzerland. E-mail: holger.moch@usz.ch

\section{References}

1. Bennington J, Beckwith J. Tumors of the Kidney, Renal Pelvis and Ureter. Vol. 12. Washington, DC: Armed Forces Institute of Pathology, 1975 .

2. Mostofi F. Histological Typing of Kidney Tumors. Vol. 25. Geneva: World Health Organization, 1981.

3. Delahunt B, Eble JN. History of the development of the classification of renal cell neoplasia. Clin Lab Med 2005; 25: 231-6.

4. Lucke B, Schlumberger H. Tumors of the Kidney, Renal Pelvis and Ureter. Vol. VIII. Washington, DC: Armed Forces Institute of Pathology, 1957.

5. Lieber M, Tomera K, Farrow G. Renal oncocytoma. J Urol 1981; 125: $481-5$.

6. Thoenes W, Störkel S, Rumpelt H, Moll R, Baum H, Werner S. Chromophobe cell renal carcinoma and its variants-a report on 32 cases. J Pathol 1988; 155: 277-87.

7. Thoenes W, Storkel S, Rumpelt HJ. Human chromophobe cell renal carcinoma. Virchows Arch B Cell Pathol Incl Mol Pathol 1985; 48 $207-17$.

8. Bannasch P, Schacht V, Storch E. Morphogenese und mikromorphologie epithelialer nierentumoren bei nitrosomorpholin vergifteten ratten. I. Induktion und histogenese der tumoren. Z Krebsforsch 1974; 81 $311-31$.

9. Thoenes W, Storkel S, Rumpelt HJ. Histopathology and classification of renal cell tumors (adenomas, oncocytomas and carcinomas). The basic cytological and histopathological elements and their use for diagnostics. Pathol Res Pract 1986; 181: 125-43.

10. Kovacs A, Kovacs G. Low chromosome number in chromophobe renal carcinoma. Genes Chromosomes Cancer 1992; 4: 267-8.

11. Kovacs G. Application of molecular cytogenetic techniques to the evaluation of renal parenchymal tumors. J Cancer Res Clin Oncol 1990; 116: $318-23$.

12. van den Berg E, van der Hout AH, Oosterhuis JW, et al. Cytogenetic analysis of epithelial renal-cell tumors: relationship with a new histopathological classification. Int J Cancer 1993; 55: 223-7.

13. Speicher M, Schoell B, Du Manoir S, et al. Specific loss of chromosomes $1,2,6,10,13,17$, and 21 in chromophobe renal cell carcinomas revealed by comparative genomic hybridization. Am J Pathol 1994; 145: 356-64.

14. Kovacs G, Akhtar M, Beckwith BJ, et al. The Heidelberg classification of renal cell tumours. J Pathol 1997; 183: 131-3.

15. Störkel S, Eble JN, Adlakha K, et al. Classification of renal cell carcinoma: workgroup No. 1. Union internationale contre le Cancer (UICC) and the American joint committee on cancer (AJCC). Cancer 1997; 80: 987-9.

16. Eble J, Sauter G, Epstein J, Sesterhenn I. Tumours of the Kidney. Tumours of the Urinary System and Male Genital Organs. Lyon: IARC Press, 2004. 
17. Moch H, Humphrey PA, Ulbright TM, Reuter V. WHO Classification of Tumours of the Urinary System and Male Genital Organs. Lyon: IARC, 2016.

18. Crotty TB, Farrow GM, Lieber MM. Chromophobe cell renal carcinoma: clinicopathological features of 50 cases. J Urol 1995; 154 964-7.

19. Cochand-Priollet B, Molinie V, Bougaran J, et al. Renal chromophobe cell carcinoma and oncocytoma. A comparative morphologic, histochemical, and immunohistochemical study of 124 cases. Arch Pathol Lab Med 1997; 121: 1081-6.

20. Amin MB, Paner GP, Alvarado-Cabrero I, et al. Chromophobe renal cell carcinoma: histomorphologic characteristics and evaluation of conventional pathologic prognostic parameters in 145 cases. Am J Surg Pathol 2008; 32: 1822-34.

21. Przybycin CG, Cronin AM, Darvishian F, et al. Chromophobe renal cell carcinoma: a clinicopathologic study of 203 tumors in 200 patients with primary resection at a single institution. Am J Surg Pathol 2011; 35: $962-70$

22. Cheville JC, Lohse CM, Sukov WR, Thompson RH, Leibovich BC Chromophobe renal cell carcinoma: the impact of tumor grade on outcome. Am J Surg Pathol 2012; 36: 851-6.

23. Casuscelli J, Becerra MF, Seier K, et al. Chromophobe renal cell carcinoma: results from a large single-institution series. Clin Genitourin Cancer 2019; 17: 373-9.

24. Vocke CD, Yang Y, Pavlovich CP, et al. High frequency of somatic frameshift BHD gene mutations in Birt-Hogg-Dube-associated renal tumors. J Natl Cancer Inst 2005; 97: 931-5.

25. Michalova K, Tretiakova M, Pivovarcikova K, et al. Expanding the morphologic spectrum of chromophobe renal cell carcinoma: a study of 8 cases with papillary architecture. Ann Diagn Pathol 2020; 44: 151448

26. Ohashi R, Martignoni G, Hartmann A, et al. Multi-institutional reevaluation of prognostic factors in chromophobe renal cell carcinoma: proposal of a novel two-tiered grading scheme. Virchows Arch 2020; 476: 409-18.

27. Akhtar M, Tulbah A, Kardar AH, Ali MA. Sarcomatoid renal cell carcinoma: the chromophobe connection. Am J Surg Pathol 1997; 21 $1188-95$.

28. Ged Y, Chen YB, Knezevic A, et al. Metastatic chromophobe renal cell carcinoma: presence or absence of sarcomatoid differentiation de termines clinical course and treatment outcomes. Clin Genitourin Cancer 2019; 17: e678-88.

29. Williamson SR, Gadde R, Trpkov K, et al. Diagnostic criteria for oncocytic renal neoplasms: a survey of urologic pathologists. Hum Pathol 2017; 63: 149-56.

30. Tickoo SK, Lee MW, Eble JN, et al. Ultrastructural observations on mitochondria and microvesicles in renal oncocytoma, chromophobe renal cell carcinoma, and eosinophilic variant of conventional (clear cell) renal cell carcinoma. Am J Surg Pathol 2000; 24: 1247-56.

31. Liu L, Qian J, Singh H, Meiers I, Zhou X, Bostwick DG. Immunohistochemical analysis of chromophobe renal cell carcinoma, renal oncocytoma, and clear cell carcinoma: an optimal and practical panel for differential diagnosis. Arch Pathol Lab Med 2007; 131: 1290-7.

32. Went P, Dirnhofer S, Salvisberg T, et al. Expression of epithelial cell adhesion molecule (EpCam) in renal epithelial tumors. Am J Surg Pathol 2005; 29: 83-8.

33. Martignoni G, Pea M, Brunelli M, et al. CD10 is expressed in a subset of chromophobe renal cell carcinomas. Mod Pathol 2004; 17: 1455-63.

34. Storkel S, Pannen B, Thoenes W, Steart PV, Wagner S, Drenckhahn D. Intercalated cells as a probable source for the development of renal oncocytoma. Virchows Arch B Cell Pathol 1988; 56: 185-9.

35. Pitz S, Moll R, Storkel S, Thoenes W. Expression of intermediate filament proteins in subtypes of renal cell carcinomas and in renal oncocytomas. Distinction of two classes of renal cell tumors. Lab Invest 1987; 56: 642-53.

36. Storkel S, Steart PV, Drenckhahn D, Thoenes W. The human chromophobe cell renal carcinoma: its probable relation to intercalated cells of the collecting duct. Virchows Arch B Cell Pathol 1989; 56: 237-45.

37. Corro C, Healy ME, Engler S, et al. IL-8 and CXCR1 expression is associated with cancer stem cell-like properties of clear cell renal cancer. J Pathol 2019; 248: 377-89.

38. Corro C, Moch H. Biomarker discovery for renal cancer stem cells J Pathol Clin Res 2018; 4: 3-18.

39. Skala SL, Wang X, Zhang Y, et al. Next-generation RNA sequencingbased biomarker characterization of chromophobe renal cell carcinoma and related oncocytic neoplasms. Eur Urol 2020; 78: 63-74.

40. Malouf GG, Su X, Zhang J, et al. DNA methylation signature reveals cell ontogeny of renal cell carcinomas. Clin Cancer Res 2016; 22: $6236-46$.

41. Young MD, Mitchell TJ, Vieira Braga FA, et al. Single-cell transcriptomes from human kidneys reveal the cellular identity of renal tumors. Science 2018; 361: 594-9.
42. Kovacs G. Molecular differential pathology of renal tumours. Histopathology 1993; 22: 1-8.

43. Bugert P, Kovacs G. Molecular differential diagnosis of renal cell carcinomas by microsatellite analysis. Am J Pathol 1996; 149: 2081-8.

44. Ohashi R, Schraml P, Batavia A, et al. Allele loss and reduced expression of CYCLOPS genes is a characteristic feature of chromophobe renal cell carcinoma. Transl Oncol 2019; 12: 1131-7.

45. Kovacs A, Storkel S, Thoenes W, Kovacs G. Mitochondrial and chromosomal DNA alterations in human chromophobe renal cell carcinomas. J Pathol 1992; 167: 273-7.

46. Welter C, Kovacs G, Seitz G, Blin N. Alteration of mitochondrial DNA in human oncocytomas. Genes Chromos Cancer 1989; 1: 79-82.

47. Yusenko MV, Ruppert T, Kovacs G. Analysis of differentially expressed mitochondrial proteins in chromophobe renal cell carcinomas and renal oncocytomas by 2-D gel electrophoresis. Int J Biol Sci 2010; 6: 213-24.

48. Davis CF, Ricketts CJ, Wang M, et al. The somatic genomic landscape of chromophobe renal cell carcinoma. Cancer Cell 2014; 26: 319-30.

49. Contractor H, Zariwala M, Bugert P, Zeisler J, Kovacs G. Mutation of the p53 tumour suppressor gene occurs preferentially in the chromophobe type of renal cell tumour. J Pathol 1997; 181: 136-9.

50. Ricketts CJ, De Cubas AA, Fan H, et al. The Cancer Genome Atlas comprehensive molecular characterization of renal cell carcinoma. Cell Rep 2018; 23: 3698.

51. Liu Q, Cornejo KM, Cheng L, et al. Next-generation sequencing to detect deletion of RB1 and ERBB4 genes in chromophobe renal cell carcinoma: a potential role in distinguishing chromophobe renal cell carcinoma from renal oncocytoma. Am J Pathol 2018; 188: 846-52.

52. Casuscelli J, Weinhold N, Gundem G, et al. Genomic landscape and evolution of metastatic chromophobe renal cell carcinoma. JCI Insight 2017: 2: e92688.

53. Ohashi R, Angori S, Batavia AA, et al. Loss of CDKN1A mRNA and protein expression are independent predictors of poor outcome in chromophobe renal cell carcinoma patients. Cancers 2020; 12: 465 .

54. Tan MH, Wong CF, Tan HL, et al. Genomic expression and singlenucleotide polymorphism profiling discriminates chromophobe renal cell carcinoma and oncocytoma. BMC Cancer 2010; 10: 196.

55. Durinck S, Stawiski EW, Pavia-Jimenez A, et al. Spectrum of diverse genomic alterations define non-clear cell renal carcinoma subtypes. Nat Genet 2015; 47: 13-21.

56. Guo T, Kouvonen P, Koh CC, et al. Rapid mass spectrometric conversion of tissue biopsy samples into permanent quantitative digital proteome maps. Nat Med 2015; 21: 407-13.

57. Zhang Y, Kwok-Shing Ng P, Kucherlapati M, et al. A pan-cancer proteogenomic atlas of PI3K/AKT/mTOR pathway alterations. Cancer Cell 2017; 31: 820-32.

58. Ohashi R, Schraml P, Angori S, et al. Classic chromophobe renal cell carcinoma incur a larger number of chromosomal losses than seen in the eosinophilic subtype. Cancers 2019; 11: 1492.

59. Brunelli M, Delahunt B, Gobbo S, et al. Diagnostic usefulness of fluorescent cytogenetics in differentiating chromophobe renal cell carcinoma from renal oncocytoma: a validation study combining metaphase and interphase analyses. Am J Clin Pathol 2010; 133: 116-26.

60. Petersson F, Gatalica Z, Grossmann P, et al. Sporadic hybrid oncocytic/ chromophobe tumor of the kidney: a clinicopathologic, histomorphologic, immunohistochemical, ultrastructural, and molecular cytogenetic study of 14 cases. Virchows Arch 2010; 456: 355-65.

61. Mikami S, Kuroda N, Nagashima Y, et al. Classification of solid renal tumor with oncocytic/eosinophilic cytoplasm: is hybrid oncocytic chromophobe renal tumor a subtype of oncocytoma, chromophobe renal cell carcinoma, or a distinct tumor entity? Ann Transl Med 2019; 7: S350.

62. Ruiz-Cordero R, Rao P, Li L, et al. Hybrid oncocytic/chromophobe renal tumors are molecularly distinct from oncocytoma and chromophobe renal cell carcinoma. Mod Pathol 2019; 32: 1698-707.

63. Waldert M, Klatte $\mathrm{T}$, Haitel A, et al. Hybrid renal cell carcinomas containing histopathologic features of chromophobe renal cell carcinomas and oncocytomas have excellent oncologic outcomes. Eur Urol 2010; 57: 661-5.

64. Aslam MI, Spencer L, Garcea G, et al. A case of liver metastasis from an oncocytoma with a focal area of chromophobe renal cell carcinoma: a wolf in sheep's clothing. Int J Surg Pathol 2009; 17: 158-62.

65. Pote N, Vieillefond A, Couturier J, et al. Hybrid oncocytic/chromophobe renal cell tumours do not display genomic features of chromophobe renal cell carcinomas. Virchows Arch 2013; 462: 633-8.

66. Mai KT, Dhamanaskar P, Belanger E, Stinson WA. Hybrid chromophobe renal cell neoplasm. Pathol Res Pract 2005; 201: 385-9.

67. Trpkov K, Yilmaz A, Uzer D, et al. Renal oncocytoma revisited: a clinicopathological study of 109 cases with emphasis on problematic diagnostic features. Histopathology 2010; 57: 893-906.

68. Benusiglio PR, Giraud S, Deveaux S, et al. Renal cell tumour characteristics in patients with the Birt-Hogg-Dube cancer susceptibility 
syndrome: a retrospective, multicentre study. Orphanet $J$ Rare Dis 2014; 9: 163 .

69. Pavlovich CP, Grubb 3rd RL, Hurley K, et al. Evaluation and management of renal tumors in the Birt-Hogg-Dube syndrome. J Urol 2005; 173: $1482-6$.

70. Srigley JR, Delahunt B, Eble JN, et al. The International Society of Urological Pathology (ISUP) Vancouver classification of renal neoplasia. Am J Surg Pathol 2013; 37: 1469-89.

71. Presti J, Moch H, Reuter V, Huynh D, Waldman F. Chromosome 1 anc 14 loss in renal oncocytomas. Genes Chromos Cancer 1996; 17: 199-204.

72. Brown JA, Takahashi S, Alcaraz A, et al. Fluorescence in situ hybridization analysis of renal oncocytoma reveals frequent loss of chromosomes Y and 1. J Urol 1996; 156: 31-5.

73. Crotty TB, Lawrence KM, Moertel CA, et al. Cytogenetic analysis of six renal oncocytomas and a chromophobe cell renal carcinoma. Evidence that $-\mathrm{Y},-1$ may be a characteristic anomaly in renal oncocytomas. Cancer Genet Cytogenet 1992; 61: 61-6.

74. Gill AJ, Hes O, Papathomas T, et al. Succinate dehydrogenase (SDH)deficient renal carcinoma: a morphologically distinct entity: a clinicopathologic series of 36 tumors from 27 patients. Am J Surg Pathol 2014; 38: $1588-602$.

75. Gill AJ, Pachter NS, Chou A, et al. Renal tumors associated with germline SDHB mutation show distinctive morphology. Am J Surg Pathol 2011; 35: 1578-85.

76. Li Y, Reuter VE, Matoso A, Netto GJ, Epstein JI, Argani P. Re-evaluation of 33 'unclassified' eosinophilic renal cell carcinomas in young patients. Histopathology 2018; 72: 588-600.

77. Perrino CM, Grignon DJ, Williamson SR, Idrees MT, Eble JN, Cheng L. Morphological spectrum of renal cell carcinoma, unclassified: an analysis of 136 cases. Histopathology 2018; 72: 305-19.

78. Tjota M, Chen H, Parilla M, Wanjari P, Segal J, Antic T. Eosinophilic renal cell tumors with a TSC and MTOR gene mutations are morphologically and immunohistochemically heterogenous: clinicopathologic and molecular study. Am J Surg Pathol 2020; 44: 943-54.

79. Chen YB, Mirsadraei L, Jayakumaran G, et al. Somatic mutations of TSC2 or MTOR characterize a morphologically distinct subset of sporadic renal cell carcinoma with eosinophilic and vacuolated cytoplasm. Am J Surg Pathol 2019; 43: 121-31.

80. Mehra R, Vats P, Cao X, et al. Somatic bi-allelic loss of TSC genes in eosinophilic solid and cystic renal cell carcinoma. Eur Urol 2018; 74 483-6.

81. Trpkov K, Hes O, Bonert M, et al. Eosinophilic, solid, and cystic renal cell carcinoma: clinicopathologic study of 16 unique, sporadic neoplasms occurring in women. Am J Surg Pathol 2016; 40: 60-71.

82. Trpkov K, Williamson SR, Gao Y, et al. Low-grade oncocytic tumour of kidney (CD117-negative, cytokeratin 7-positive): a distinct entity? Histopathology 2019; 75: 174-84.

83. Shah RB, Stohr BA, Tu ZJ, et al. "Renal cell carcinoma with leiomyomatous stroma" harbor somatic mutations of TSC1, TSC2, MTOR and/or ELOC (TCEB1): clinicopathologic and molecular characterization of 18 sporadic tumors supports a distinct entity. Am J Surg Pathol 2020; 44: 571-81.
84. Renshaw AA, Richie JP. Subtypes of renal cell carcinoma. Differen onset and sites of metastatic disease. Am J Clin Pathol 1999; 111 $539-43$.

85. Amin M, Moch H, Amin M, et al. Chromophobe renal cell carcinoma (CH-RCC): a study of 65 cases. Annual meeting, United States and Canadian Academy of Pathology, 1999: 88A.

86. Paner GP, Amin MB, Alvarado-Cabrero I, et al. A novel tumor grading scheme for chromophobe renal cell carcinoma: prognostic utility anc comparison with Fuhrman nuclear grade. Am J Surg Pathol 2010; 34: $1233-40$.

87. Moch H, Gasser T, Amin MB, Torhorst J, Sauter G, Mihatsch MJ. Prognostic utility of the recently recommended histologic classification and revised TNM staging system of renal cell carcinoma: a Swiss experience with 588 tumors. Cancer 2000; 89: 604-14.

88. de Peralta-Venturina M, Moch H, Amin M, et al. Sarcomatoid differentiation in renal cell carcinoma: a study of 101 cases. Am J Surg Patho 2001; 25: 275-84.

89. Delahunt B, Sika-Paotonu D, Bethwaite PB, et al. Fuhrman grading is not appropriate for chromophobe renal cell carcinoma. Am J Surg Patho 2007; 31: 957-60.

90. Finley DS, Shuch B, Said JW, et al. The chromophobe tumor grading system is the preferred grading scheme for chromophobe renal cel carcinoma. J Urol 2011; 186: 2168-74.

91. Renshaw A, Henske E, Loughlin K, Shapiro C, Weinberg D. Aggressive variants of chromophobe renal cell carcinoma. Cancer 1996; 78: 1756-61.

92. Lohse CM, Blute ML, Zincke H, Weaver AL, Cheville JC. Comparison of standardized and nonstandardized nuclear grade of renal cell carcinoma to predict outcome among 2,042 patients. Am J Clin Pathol 2002; 118: $877-86$.

93. Debien V, Thouvenin J, Lindner V, et al. Sarcomatoid dedifferentiation in renal cell carcinoma: from novel molecular insights to new clinical opportunities. Cancers 2019; 12: 99.

94. Jiang F, Moch H, Richter J, et al. Comparative genomic hybridization reveals frequent chromos $13 \mathrm{q}$ and $4 \mathrm{q}$ losses in renal cell carcinomas with sarcomatoid transformation. J Pathol 1998; 185: 382-8.

95. Montironi R, Cimadamore A, Ohashi R, et al. Chromophobe renal cell carcinoma aggressiveness and immuno-oncology therapy: how to distinguish the good one from the bad one. Eur Urol Oncol 2020; 18 s2588-9311.

96. Cimadamore A, Cheng L, Ohashi R, et al. Re: multi-institutional reevaluation of prognostic factors in chromophobe renal cell carcinoma: proposal of a novel two-tiered grading scheme. Eur Urol 2020; 78: 114-6.

97. Choueiri TK, Motzer RJ. Systemic therapy for metastatic renal-cell carcinoma. N Engl J Med 2017; 376: 354-66.

98. Kwiatkowski DJ, Choueiri TK, Fay AP, et al. Mutations in TSC1, TSC2, and MTOR are associated with response to rapalogs in patients with metastatic renal cell carcinoma. Clin Cancer Res 2016; 22: $2445-52$.

99. Sakamoto H, Yamasaki T, Sumiyoshi T, et al. A family case with germline TSC1 and mtDNA mutations developing bilateral eosinophilic chromophobe renal cell carcinomas without other typical phenotype of tuberous sclerosis. J Clin Pathol 2018; 71: 936-43. 